\title{
IMPLANTAÇÃO DO PROCESSO DE GERENCIAMENTO DE TEMPO: UM ESTUDO DE CASO EM UMA EMPRESA DE ENGENHARIA DO CEARÁ
}

\author{
Geam Carlos de Araujo Filgueira ${ }^{1}$, Emanuel Dantas Filho ${ }^{2}$, Karlos T. M. V Oliveira ${ }^{1}$, \\ Jannayna Domingues Barros Filgueira ${ }^{3}$, MARCus Vinícius NobregA ${ }^{4}$ \\ ${ }^{1}$ Instituto Federal de Educação, Ciência e Tecnologia do Rio Grande do Norte (IFRN) \\ ${ }^{2}$ Instituto Federal de Educação, Ciência e Tecnologia do Ceará (IFCE) \\ ${ }^{3}$ Universidade Estadual da Paraíba (UEPB) \\ ${ }^{4}$ Instituto de Pós-Graduação - IPOG. MBA Gestão de Projetos em Engenharias e Arquitetura \\ <geam.filgueira@ifrn.edu.br>, <emanuel.filho@ifce.edu.br> \\ <karlos.oliveira@ifrn.edu.br>, <jannayna@uepb.edu.br>, <mvmnobrega@gmail.com>
}

DOI: 10.21439/conexoes.v10i2.768

\begin{abstract}
Resumo. O uso da metodologia de Gerenciamento de Projetos tem se tornado um diferencial em empresas de todos os setores. Em especial, a área de Gerenciamento de Tempo mostra-se como uma das mais importantes e que possibilita grandes avanços para as organizações, de acordo com o modelo proposto pelo Project Management Body of Knowledge - PMBOK. Este artigo trata de um estudo de caso de implantação de processos dessa área em uma empresa atuante no mercado de energias renováveis, localizada em Fortaleza, estado do Ceará. Os atrasos corriqueiros nas entregas de projetos elétricos de parques eólicos, bem como a sobrecarga gerada sobre equipe desenvolvedora dos projetos motivou a necessidade desse estudo. Neste cenário, o objetivo desse trabalho é criar um plano de gerenciamento de tempo elaborado em consonância com as recomendações da $4^{\mathrm{a}}$ edição do PMBOK. Como insumos para elaboração do plano serão utilizados dados históricos de projetos anteriores e a mão de obra disponível no departamento de projetos elétricos. Como resultados, com adoção do plano de gerenciamento de tempo em dois casos reais de projetos analisados do departamento, foi verificado a eliminação de atrasos em entregas e baixa sobrecarga de trabalho da equipe.
\end{abstract}

Palavras-chaves: Projetos. Gerenciamento de Tempo. PMBOK.

\begin{abstract}
The use of Project Management methodology has become a differential in all sectors. In particular, the Time Management area shows up as one of the most important and enabling great advances for organizations, according to the model proposed by the Project Management Body of Knowledge PMBOK. This article is a case study of implementation processes of this area in a company active in the renewable energy market, located in Fortaleza, Ceará. The commonplace delays in deliveries of electrical projects of wind farms as well as the overhead generated on developer projects motivated team of the need for this study. In this scenario, our aim is to create a time management plan prepared in accordance with the recommendations of the 4th edition of the PMBOK. As inputs for preparation of the plan will be used historical data from previous projects and the manpower available in the electrical design department. As a result, with adoption of time management plan in two real cases analyzed projects of the department, was found to eliminate delays in deliveries and low staff workload.
\end{abstract}

Keywords: Project. Time Management. PMBOK.

\section{INTRODUÇÃO}

Atualmente, o crescente surgimento de pequenas empresas pelo mundo é acompanhado de uma alta taxa de mortalidade em seus primeiros anos de vida. As principais causas relatadas por Junior e Everton (2000) são o baixo nível de formação educacional e a pouca ou ne- 
IMPLANTAÇÃO DO PROCESSO DE GERENCIAMENTO DE TEMPO: UM ESTUDO DE CASO EM UMA EMPRESA DE ENGENHARIA DO CEARÁ

nhuma experiência administrativa dos empresários.

Para Fraga e Tolentino (2013), as exigências na atuação profissional e excelência operacional têm transformado as expectativas mais desafiadoras em empresas desse porte devido à limitação de recursos humanos, financeiros e de infraestrutura. Em geral, a forma obtida pelas organizações com objetivo de desenvolvimento tem sido através do instrumento de gerenciamento de projetos.

Segundo Bouer e Carvalho (2005, p. 1), "modelos de maturidade em gerenciamento de projetos vêm obtendo notoriedade, como instrumento de análise e melhoria de projetos, de forma a desenvolver competências organizacionais em gerenciamento de projetos".

As empresas e os gerentes de projetos têm investido no treinamento, processos, ferramentas e estruturas para aumentar a maturidade de um ambiente de gerenciamento. Contudo, é possível observar vários problemas ligados a essa prática. Muitos deles estão ligados a uma das variáveis mais imponderáveis e implacáveis de todas: o tempo. (BARCAUI apud PANIGAS, 2012, p.5).

Panigas (2012) lembra que o tempo é o único recurso impossível de ser recuperado na execução de um projeto, fato que concede uma maior visibilidade a essa variável, que se controlada devidamente, maximiza a possibilidade de sucesso em um projeto.

Nesse contexto, este trabalho tem como objetivo apresentar um plano de gerenciamento de tempo para elaboração de projetos básicos elétricos de parques eólicos em uma empresa atuante no mercado de energias renováveis.

A motivação do trabalho foi subsidiar a diretoria da empresa quanto ao tempo e recursos necessários para elaboração de um projeto básico, tendo em vista problemas surgidos recentemente, como o não cumprimento dos prazos de entrega e a sobrecarga da equipe de projetos elétricos, os quais poderiam causar insatisfação de clientes e funcionários.

O trabalho está organizado da seguinte forma: introdução e contextualização ao assunto, no detalhamento do Gerenciamento de Projetos, com ênfase na disciplina de Gerenciamento de Tempo. Em seguida, é apresentada a metodologia adotada na pesquisa e a análise dos dados obtidos e catalogados. Por fim, serão apresentadas as considerações finais do trabalho e as referências bibliográficas.

\section{FUNDAMENTAÇÃO TEÓRICA}

A fundamentação teórica apresenta uma revisão da literatura buscando evidenciar os conceitos que serviram como base para o desenvolvimento da pesquisa. Inicialmente são abordados os conceitos do gerenciamento de riscos segundo o PMBOK e, em seguida um estudo do gerenciamento de tempo.

\subsection{Project Management Body of Knowledge (PM- BOK)}

O PMBOK Guide é o principal documento de referência do PMI - Project Management Institute. É um guia de conhecimentos de gerenciamento de projetos e, atualmente, encontra-se em sua quinta edição, lançada em 2013.

Conforme descrito em seu objetivo:

Guia PMBOK identifica o subconjunto do conhecimento em gerenciamento de projetos amplamente reconhecido como boa prática. "Amplamente reconhecido" significa que o conhecimento e as práticas descritas são aplicáveis à maioria dos projetos na maior parte do tempo, e que existe um consenso geral em relação ao seu valor e sua utilidade. "Boa prática" significa que existe consenso geral de que a aplicação correta dessas habilidades, ferramentas e técnicas podem aumentar as chances de sucesso em uma ampla gama de projetos. (PMBOK, 2008, p. 4).

\subsection{Gerenciamento de Tempo}

De acordo com escritor austríaco Peter Drucker, "o tempo é o recurso mais escasso e, a não ser que seja gerido, nada mais pode ser gerido".

Para gerenciar o término pontual de um projeto, definem-se como necessários seis processos (PMBOK , 2008, p. 112).

- Definir as atividades - O processo de identificação das ações específicas a serem realizadas para produzir as entregas do projeto.

- Sequenciar as atividades - O processo de identificação e documentação dos relacionamentos entre as atividades do projeto.

- Estimar os recursos da atividade - O processo de estimativa dos tipos e quantidades de material, pessoas, equipamentos ou suprimentos que serão necessários para realizar cada atividade. 


\section{IMPLANTAÇÃO DO PROCESSO DE GERENCIAMENTO DE TEMPO: UM ESTUDO DE CASO EM UMA EMPRESA DE}

ENGENHARIA DO CEARÁ

- Estimar as durações da atividade - O processo de estimativa do número de períodos de trabalho que serão necessários para terminar atividades específicas com os recursos estimados.

- Desenvolver o cronograma - O processo de análise das sequências das atividades, suas durações, recursos necessários e restrições do cronograma visando criar o cronograma do projeto.

- Controlar o cronograma - O processo de monitoramento do andamento do projeto para atualização do seu progresso e gerenciamento das mudanças feitas na linha de base do cronograma.

O organograma ilustrado na Figura 1 resume os seis processos do gerenciamento do tempo em um projeto conforme preceitos da $4^{\mathrm{a}}$ edição PMBOK.

\subsection{Método do Caminho Crítico (PERT/CPM)}

Desenvolvidos no final da década de 1950, os métodos PERT - Program Evaluation and Review Technique e CPM - Critical Path Method tem sido, desde então, bastante aplicados no processo de planejamento e controle de projetos (PANIGAS, 2012).

Enquanto PERT calcula através de uma média ponderada de três durações possíveis de uma atividade (otimista, mais provável e pessimista), CPM utiliza uma metodologia de apuração do caminho crítico, dada uma sequência de atividades, ou seja, quais atividades não podem sofrer alteração de duração dentro de uma sequencia sem que isso reflita na duração total de um projeto (COSTA, 2013).

Panigas (2012) relata que apesar de terem sido desenvolvidos de forma independente, os métodos PERT e CPM, devido às suas semelhanças na forma de determinação e projeto de atividades, são utilizados corriqueiramente como método único, ao ponto de terem seus nomes unidos.

Panigas (2012) ainda acrescenta que PERT/CPM constitui-se em uma técnica que permite uma melhor coordenação das atividades através de uma rede ou grafos das relações sequenciais de interdependência, com definição dos tempos parciais e totais de duração do projeto, possibilitando uma visualização global do projeto. Desta forma, fica mais clara a visualização de folgas existentes entre as atividades do projeto.

\subsection{Microsoft Project}

O Microsoft Project, popularmente denominado de MS project, é um software desenvolvido pela Microsoft $\mathbb{R}$ inicialmente em 1985. Moreira, Silva e Palma (2010) lembra que seus atributos permitem aos usuários planejar, programar e demonstrar graficamente informações sobre projetos.

Segundo Pinto (2010) em empresas do Brasil o MS Project é software mais utilizado como apoio ao gerenciamento de projetos, com aproximadamente 76,1

As principais funcionalidades do MS Project como software aplicado no segmento da gerência de projetos são (PIMENTEL, 2008, p. 36):

- Criar, editar e controlar um projeto;

- Personalização para diferentes metodologias e produtividade;

- Criar gráficos, relatórios e diagramas profissionais;

- Permitir tarefas recorrentes;

- Maior controle de informações, finanças e prazos;

- Acesso rápido às informações desejadas.

\section{METODOLOGIA DA PESQUISA}

A forma de pesquisa foi a Descritiva: visa descrever as características de determinada população ou fenômeno, ou o estabelecimento de relações entre variáveis. Com relação aos procedimentos técnicos, esta pesquisa foi realizada via Internet, com consultas nos principais portais de meio científico.

Em um primeiro momento, para ter um direcionamento para escrita do plano, foi realizado um estudo sobre os processos de Gerenciamento de Tempo do PMBOK. Posteriormente, para ter insumos para construção do plano, objetivo desse trabalho, foi analisado a base histórica de projetos encerrados da empresa, em um total de doze projetos concluídos.

Com o estudo dos processos do PMBOK e análise do comportamento e características dos projetos da empresa, o próximo passo foi a elaboração do plano de gerenciamento de tempo. Como estudo de caso foram escolhidos dois projetos que estavam na iminência de iniciar.

A implantação do plano foi realizada durante dois meses, período suficiente para aplicá-lo nos dois projetos. Durante a execução dos projetos foram analisadas variáveis relacionados ao tempo que os recursos levaram para concluir cada atividade. Por fim, os resultados da aplicação do plano foram coletados para realização de uma análise final. 


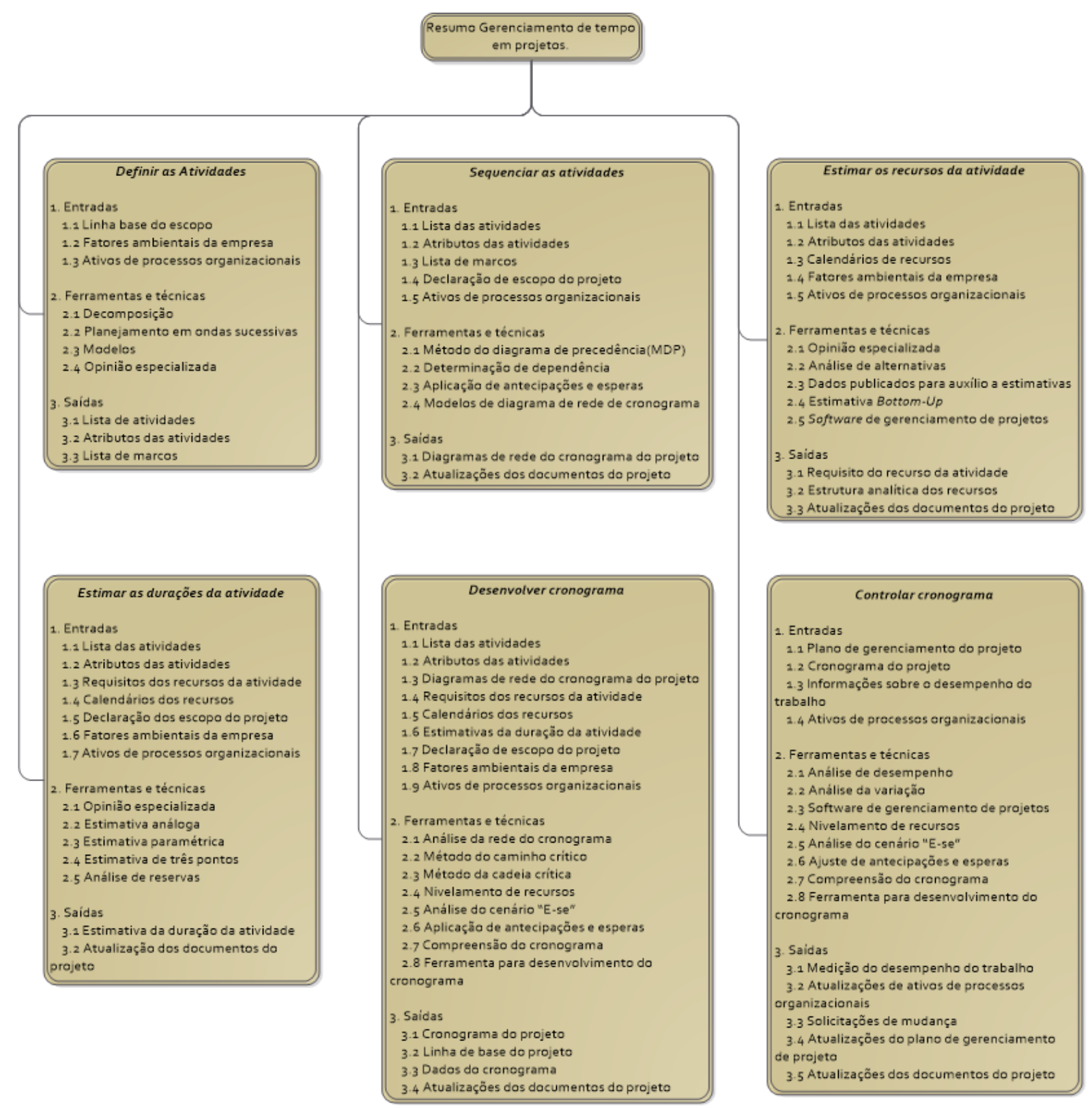

Figura 1: Resumo do gerenciamento do tempo de um projeto. 
IMPLANTAÇÃO DO PROCESSO DE GERENCIAMENTO DE TEMPO: UM ESTUDO DE CASO EM UMA EMPRESA DE ENGENHARIA DO CEARÁ

\section{ESTUDO DE CASO}

O estudo de caso ocorre em uma pequena empresa atuante na área de energias renováveis, localizada em Fortaleza, Ceará. Neste trabalho será designado o codinome MVMN Energia para a empresa.

O sucesso obtido pelos parques eólicos nos leilões de energia resultou no aumento de demanda dos projetos básicos na MNMN Energia, tornando-os um dos principais produtos fornecidos pela empresa. Nesse contexto, tornaram-se corriqueiros atrasos em entregas e sobrecarga da equipe de projetos.

Com base no conteúdo apresentado na seção 2 deste trabalho, o plano de gerenciamento do tempo tomará como referência as recomendações da $4^{\mathrm{a}}$ edição do PMBOK no gerenciamento do tempo, a saber: definição de atividades, sequenciar atividades, estimar os recursos da atividade, estimar durações das atividades, desenvolver cronograma e controlar cronograma.

O plano elaborado pelo autor cobre todas essas atividades e foi executado com o auxílio do software MS Project, versão 2010.

\subsection{Definição das Atividades}

As atividades a serem realizadas no projeto foram decompostas em três pacotes de trabalho: planejamento, desenvolvimento e término. O objetivo desta subdivisão é tornar o trabalho mais gerenciável.

A lista de atividades desenvolvidas no projeto básico é apresentada a seguir na Tabela 1 .

\subsection{Sequência das Atividades}

O diagrama de rede ilustrado na Figura 2 representa a ordem de sequenciamento das atividades realizadas no projeto. Apenas o tipo de dependência com término para início (TI) foi aplicado no plano de gerenciamento devido à elaboração de atividades sequentes estar vinculada ao término de alguma atividade anterior.

\subsection{Estimativa dos Recursos}

Para elaboração do projeto básico serão utilizados no total de cinco recursos: engenheiro 1 (coordenador de projeto), engenheiro 2 , projetista 1 , projetista 2 e empresa terceira, esta última responsável pela plotagem dos desenhos do projeto.

A Tabela 2 lista a associação entre pacotes de trabalho, atividades e recursos utilizados no projeto.

\subsection{Estimativa da Duração das Atividades}

A técnica adotada para definição das durações de cada tarefa foi a de estimativa análoga a qual usa parâme- tros de duração referenciados a projetos similares como base. A duração, atividade e seu respectivo pacote de trabalho encontram-se listados na Tabela $3 \mathrm{em}$ seguida.

\subsection{Desenvolvimento do Cronograma}

Baseado nos itens 2.1, 2.2, 2.3 e 2.4 deste trabalho, um cronograma base foi desenvolvido para implantação do projeto básico, conforme apresentado na Figura 3 O cronograma é apresentado na forma de Gráfico de Gantt.

\subsection{Controle do Cronograma}

O controle e atualização do cronograma foram realizados duas vezes por semana, às quartas e sextas-feiras, devido à curta duração do projeto. Foi evidenciado na análise do cronograma o andamento das tarefas críticas como sequenciadas na Figura 4, a seguir. Sempre quando possível, a antecipação de tarefas críticas será realizada como ação preventiva para cumprimento do prazo estabelecido no cronograma.

\section{RESULTADOS}

Os resultados obtidos da implantação do plano de gerenciamento de tempo em dois projetos básicos são apresentados na Tabela 4 .

\section{CONCLUSÕES E CONSIDERAÇÕES FINAIS}

A aplicação do plano de gerenciamento de tempo para elaboração de projetos básicos elétricos na MVMN Energia mostrou-se bastante satisfatória.

A definição das atividades do projeto associada à ordem sequencial, recursos e duração de cada atividade contribuiu para a sinergia da equipe de projetos, onde cada funcionário absorveu sua importância e responsabilidade perante cada fase do projeto.

O desenvolvimento e controle do cronograma, prática até então não aplicada em projetos desse porte devido à sua curta duração, foi de suma importância para o acompanhamento geral das atividades, subsidiando o coordenador do projeto na tomada de decisões para possíveis riscos que resultem no atraso do projeto.

A eficiência do plano desenvolvido foi comprovada durante sua aplicação em dois projetos, onde o primeiro foi concluído com 17 dias e o segundo com 18 dias, prazo limite definido no plano. Em ambos os casos não foi observada sobrecarga em qualquer componente de equipe desenvolvedora do projeto.

Esses resultados foram repassados para a diretoria da empresa para que as propostas comerciais tomem 
IMPLANTAÇÃO DO PROCESSO DE GERENCIAMENTO DE TEMPO: UM ESTUDO DE CASO EM UMA EMPRESA DE ENGENHARIA DO CEARÁ

Tabela 1: Lista de Atividades do Projeto Básico.

\begin{tabular}{|c|c|c|}
\hline \multicolumn{2}{|c|}{ Pacote de trabalho } & Atividade \\
\hline \multirow{11}{*}{\multicolumn{2}{|c|}{ Planejamento }} & Avaliar premissas e requisitos definidos pelo cliente \\
\hline & & Verificar lições aprendidas em projetos semelhantes \\
\hline & & Analisar micrositing do parque eólico \\
\hline & & Avaliar estudos elétricos de conexão \\
\hline & & $\begin{array}{l}\text { Avaliar requisitos solicitados pela distribuidora ou } \\
\text { transmissora de energia }\end{array}$ \\
\hline & & Estudar documentação técnica do a erogera dor \\
\hline & & Definir localização da subestação \\
\hline & & Definir circuitos da rede intema de média tensão \\
\hline & & Definir circuito de aterramento \\
\hline & & Definir circuito de comunicação \\
\hline & & $\begin{array}{l}\text { Observar altemativas de traçado para linha de } \\
\text { transmissão }\end{array}$ \\
\hline \multirow{9}{*}{ Desenvolvimento } & \multirow{4}{*}{ Documentos gerais } & Esquema geral de conexão \\
\hline & & Memóna de cálculo de perdas elétricas \\
\hline & & Memorial descritivo \\
\hline & & Anotação de Responsabilidade Técnica (ART) \\
\hline & \multirow{5}{*}{ Subestação Elevadora } & Diagrama unifilar AT/MT \\
\hline & & Diagrama unifilar CA \\
\hline & & Diagrama unifilar CC \\
\hline & & Planta baixa do pátio \\
\hline & & Cortes do pátio \\
\hline \multirow{10}{*}{ Desenvolvimento } & \multirow{3}{*}{ Subestação Elevadora } & Planta baixa da casa de comando \\
\hline & & Cortes da casa de comando \\
\hline & & Lista de principais equipamentos \\
\hline & \multirow{5}{*}{$\begin{array}{l}\text { Rede intema de } \\
\text { média tensão }\end{array}$} & Planta geral do traçado da RMT \\
\hline & & Memóna de cálculo dos cabos MT \\
\hline & & Diagrama unifilar MT/BT \\
\hline & & Lista de cabos e componentes \\
\hline & & Lista de materiais e serviços \\
\hline & \multirow{2}{*}{ Linha de Transmissão } & Planta geral do traçado da LT \\
\hline & & Lista de cabos, estruturas e componentes. \\
\hline \multirow{2}{*}{\multicolumn{2}{|c|}{ Término }} & Entrega em meio digital \\
\hline & & Entrega em meio fisico \\
\hline
\end{tabular}

Conex. Ci. e Tecnol. Fortaleza/CE, v. 10, n. 2, p. 61 - 72, jul. 2016 
Tabela 2: Lista de Atividades do Projeto Básico.

\begin{tabular}{|c|c|c|c|}
\hline \multicolumn{2}{|c|}{ Pacote de trabalho } & Atividade & Recurso(s) \\
\hline \multirow{11}{*}{\multicolumn{2}{|c|}{ Planejamento }} & $\begin{array}{l}\text { Avaliar premissas e requisitos definidos } \\
\text { pelo cliente }\end{array}$ & Equipe de projetos \\
\hline & & $\begin{array}{l}\text { Verificar liçőes aprendidas em projetos } \\
\text { semelhantes }\end{array}$ & Equipe de projetos \\
\hline & & Analisar micrositing do parque eólico & Equipe de projetos \\
\hline & & Avaliar estudos elétricos de conexão & Equipe de projetos \\
\hline & & $\begin{array}{l}\text { Avaliar requisitos solicitados pela } \\
\text { distribuidora ou transmissora de energia }\end{array}$ & Equipe de projetos \\
\hline & & $\begin{array}{l}\text { Estudar documentação técnica do } \\
\text { aerogerador }\end{array}$ & Equipe de projetos \\
\hline & & Definir localização da subestação & Equipe de projetos \\
\hline & & $\begin{array}{l}\text { Definir circuitos da rede interna de média } \\
\text { tensão }\end{array}$ & Equipe de projetos \\
\hline & & Definir circuito de aterramento & Equipe de projetos \\
\hline & & Defmir circuito de comunicação & Equipe de projetos \\
\hline & & $\begin{array}{l}\text { Observar alternativas de traçado para limha } \\
\text { de transmissão }\end{array}$ & Equipe de projetos \\
\hline \multirow{4}{*}{\multicolumn{2}{|c|}{$\begin{array}{l}\text { Documentos } \\
\text { gerais }\end{array}$}} & Esquema geral de conexão & Engenheiros 1 e 2 \\
\hline & & Memória de calculo de perdas elétricas & Engenheiro 2 \\
\hline & & Memorial descritivo & Engenheiros 1 e 2 \\
\hline & & $\begin{array}{l}\text { Anotaçåo de Responsabilidade Técnica } \\
\text { (ART) }\end{array}$ & Engenheiro 1 \\
\hline \multirow{15}{*}{ Desenvolvimento } & \multirow{8}{*}{$\begin{array}{l}\text { Subestação } \\
\text { Elevadora }\end{array}$} & Diagrama unifilar AT/MT & Engenheiro 1 \\
\hline & & Diagrama unifilar CA & Engenheiro 1 \\
\hline & & Diagrama unifilar CC & Engenheiro 1 \\
\hline & & Planta baixa do pátio & Projetista 1 \\
\hline & & Cortes do pátio & Projetista 1 \\
\hline & & Planta baixa da casa de comando & Projetista 1 \\
\hline & & Cortes da casa de comando & Projetista 1 \\
\hline & & Lista de principais equipamentos & Projetista 1 \\
\hline & \multirow{5}{*}{$\begin{array}{l}\text { Rede interna de } \\
\text { média tensão }\end{array}$} & Planta geral do traçado da RMT & $\begin{array}{l}\text { Engenheiro } 2 \text {, } \\
\text { Projetista } 2\end{array}$ \\
\hline & & Memória de cáculo dos cabos MT & Engenheiro 2 \\
\hline & & Diagrama unifilar MT/BT & Engenheiro 2 \\
\hline & & Lista de cabos e componentes & Engenheiro 2 \\
\hline & & Lista de materiais e serviços & Engenheiro 2 \\
\hline & \multirow{2}{*}{$\begin{array}{l}\text { Linha de } \\
\text { Transmissão }\end{array}$} & Planta geral do traçado da LT & Projetista 2 \\
\hline & & Lista de cabos, estruturas e componentes & Engenheiro 1 \\
\hline \multirow{2}{*}{\multicolumn{2}{|c|}{ Término }} & Entrega em meio digital & Engenheiro 1 \\
\hline & & Entrega em meio fisico & Empresa terceirizada \\
\hline
\end{tabular}


IMPLANTAÇÃO DO PROCESSO DE GERENCIAMENTO DE TEMPO: UM ESTUDO DE CASO EM UMA EMPRESA DE ENGENHARIA DO CEARÁ

Tabela 3: Duração das Atividades.

\begin{tabular}{|c|c|c|c|}
\hline \multicolumn{2}{|c|}{ Pacote de trabalho } & Atividade & Duracão \\
\hline \multirow{5}{*}{\multicolumn{2}{|c|}{ Planejamento }} & $\begin{array}{l}\text { Avaliar premissas e requisitos definidos pelo } \\
\text { cliente }\end{array}$ & 3 dias \\
\hline & & $\begin{array}{l}\text { Verificar liçóes aprendidas em projetos } \\
\text { semelhantes }\end{array}$ & 3 dias \\
\hline & & Analisar micrositing do parque eólico & 3 dias \\
\hline & & Avaliar estudos elétricos de conexão & 3 dias \\
\hline & & $\begin{array}{l}\text { Avaliar requisitos solicitados pela distribuidora } \\
\text { ou transmissora de energia }\end{array}$ & 3 dias \\
\hline \multirow{6}{*}{\multicolumn{2}{|c|}{ Planejamento }} & Estudar documentação técnica do aerogerador & 3 dias \\
\hline & & Definir localização da subestaçăo & 3 dias \\
\hline & & Defmir circuitos da rede interna de média tensăo & 3 dias \\
\hline & & Defmir circuito de aterramento & 3 dias \\
\hline & & Definir circuito de comunicação & 3 dias \\
\hline & & $\begin{array}{l}\text { Observar alternativas de traçado para linha de } \\
\text { transmissão }\end{array}$ & 3 dias \\
\hline \multirow{4}{*}{\multicolumn{2}{|c|}{$\begin{array}{l}\text { Documentos } \\
\text { gerais }\end{array}$}} & Esquema geral de conexão & 1 dia \\
\hline & & Memória de cálculo de perdas elétricas & 1 dia \\
\hline & & Memorial descritivo & 4 dias \\
\hline & & Anotaçăo de Responsabilidade Técnica (ART) & O dia \\
\hline \multirow{15}{*}{ Desenvolvimento } & \multirow{8}{*}{$\begin{array}{l}\text { Subestação } \\
\text { Elevadora }\end{array}$} & Diagrama unifilar AT/MT & 2 dias \\
\hline & & Diagrama unifilar CA & 2 dias \\
\hline & & Diagrama unifilar CC & 2 dias \\
\hline & & Planta baixa do pátio & 2 dias \\
\hline & & Cortes do pátio & 2 dias \\
\hline & & Planta baixa da casa de comando & 2 dias \\
\hline & & Cortes da casa de comando & 2 dias \\
\hline & & Lista de principais equipamentos & 1 dia \\
\hline & \multirow{5}{*}{$\begin{array}{l}\text { Rede interna de } \\
\text { média tensão }\end{array}$} & Planta geral do traçado da RMT & 2 dias \\
\hline & & Memória de cálculo dos cabos MT & 2 dias \\
\hline & & Diagrama unifilar MT/BT & 1 dia \\
\hline & & Lista de cabos e componentes & 1 dia \\
\hline & & Lista de materiais e serviços & 1 dia \\
\hline & \multirow{2}{*}{$\begin{array}{c}\text { Linha de } \\
\text { Transmissão }\end{array}$} & Planta geral do traçado da LT & 2 dias \\
\hline & & Lista de cabos, estruturas e componentes & 1 dia \\
\hline \multirow{2}{*}{\multicolumn{2}{|c|}{ Término }} & Entrega em meio digital & O dia \\
\hline & & Entrega em meio fisico & 2 dias \\
\hline
\end{tabular}

Conex. Ci. e Tecnol. Fortaleza/CE, v. 10, n. 2, p. 61 - 72, jul. 2016 
Tabela 4: Duração das Atividades.

\begin{tabular}{|c|c|c|c|}
\hline Nome da tarefa & $\begin{array}{c}\text { Plano } \\
\text { elaborado } \\
\text { (dias) }\end{array}$ & \begin{tabular}{|c|} 
Projeto \\
1 \\
(dias) \\
\end{tabular} & $\begin{array}{c}\text { Projeto } \\
2 \\
\text { (dias) } \\
\end{array}$ \\
\hline Projeto Básico Elétrico & 18 & 17 & 18 \\
\hline Planejamento & 3 & 3 & 4 \\
\hline Avaliar premissas e requisitos definidos pelo cliente & 3 & 3 & 3 \\
\hline Verificar lições aprendidas em projetos semelhantes & 3 & 2 & 2 \\
\hline Analisar micrositing do parque eólico & 3 & 1 & 2 \\
\hline Avaliar estudos elétricos de conexão & 3 & 3 & 2 \\
\hline $\begin{array}{l}\text { Avaliar requisitos solicitados pela distribuidora ou transmissora de } \\
\text { energia }\end{array}$ & 3 & 3 & 3 \\
\hline Estudar documentação técnica do aerogerador & 3 & 3 & 3 \\
\hline Definir localização da subestação & 3 & 1 & 2 \\
\hline Definir circuitos da rede interna de média tensão & 3 & 3 & 3 \\
\hline Definir circuito de aterramento & 3 & 3 & 3 \\
\hline Definir circuito de comunicação & 3 & 3 & 3 \\
\hline Observar alternativas de traçado para linha de transmissão & 3 & 3 & 4 \\
\hline Término do planejamento & 0 & 0 & 0 \\
\hline Geral & 13 & 12 & 13 \\
\hline Esquema geral de conexão & 1 & 1 & 1 \\
\hline Memória de cálculo de perdas elétricas & 1 & 1 & 2 \\
\hline Memorial descritivo & 4 & 4 & 4 \\
\hline Emitir ART & 0 & 0 & 0 \\
\hline Subestação Elevadora & 10 & 8 & 7 \\
\hline Diagrama Unifilar AT/MT & 2 & 2 & 1 \\
\hline Diagrama unifilar CA & 2 & 2 & 2 \\
\hline Diagrama unifilar CC & 2 & 1 & 2 \\
\hline Planta baixa do pátio & 2 & 2 & 2 \\
\hline Cortes do pátio & 2 & 1 & 1 \\
\hline Planta baixa da casa de comando & 2 & 1 & 1 \\
\hline Cortes da casa de comando & 2 & 2 & 1 \\
\hline Lista de principais equipamentos & 1 & 1 & 1 \\
\hline Término Subestação Elevadora & 0 & 0 & 0 \\
\hline Rede interna de média tensão & 7 & 6 & 7 \\
\hline Planta geral do traçado da rede & 2 & 2 & 3 \\
\hline Memória de cálculo dos cabos & 2 & 1 & 1 \\
\hline Diagrama unifilar MT/BT & 1 & 1 & 1 \\
\hline Lista de cabos e componentes & 1 & 1 & 1 \\
\hline Lista de materiais e serviços & 1 & 1 & 1 \\
\hline Término Rede de média tensão & 0 & 0 & 0 \\
\hline Linha de transmissão & 5 & 5 & 5 \\
\hline Planta geral do traçado da linha & 2 & 2 & 2 \\
\hline Lista de cabos, estruturas e componentes & 1 & 1 & 1 \\
\hline Término linha de transmissão & 0 & 0 & 0 \\
\hline Término & 2 & 2 & 1 \\
\hline Entrega meio digital & 0 & 0 & 0 \\
\hline Entrega meio físico & 2 & 2 & 1 \\
\hline Projeto finalizado & 0 & 0 & 0 \\
\hline
\end{tabular}

Conex. Ci. e Tecnol. Fortaleza/CE, v. 10, n. 2, p. 61 - 72, jul. 2016 


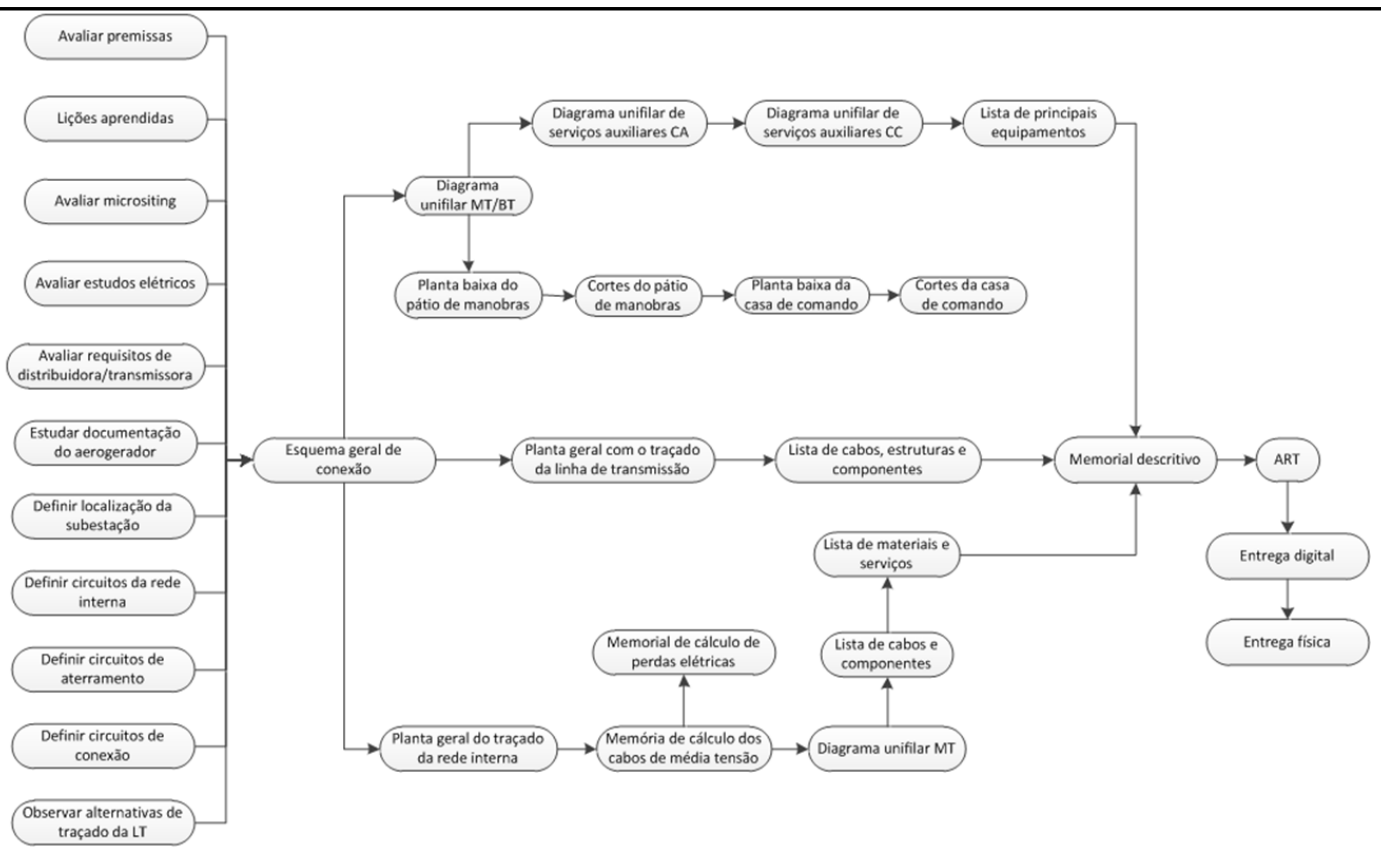

Figura 2: Diagrama de rede do projeto básico.

como referência o prazo de execução dos serviços em aproximadamente 18 dias.

Como perspectivas futuras, pretende-se usar a experiência desse estudo de caso na implantação do plano de gerenciamento de tempo em outros projetos da empresa. Um fator que também precisa ser observado é analisar os resultados considerando projetos com execução paralela. Os projetos desse estudo de caso aconteceram em momentos distintos.

\section{REFERÊNCIAS}

BOUER, R.; CARVALHO, M. M. d. Metodologia singular de gestão de projetos: condição suficiente para a maturidade em gestão de projetos? Production, scielo, v. 15, p. 347 361, 12 2005. ISSN 0103-6513. Disponível em: $<$ http://www.scielo.br/scielo.php?script=sci_arttext\& pid=S0103-65132005000300006\&nrm=iso $>$

COSTA, T. Pesquisa operacional: teoria das Restrições, Pert, CPM e corrente crítica. jan. 2013. Disponível em: <http://migre.me/sWH3v> Acesso em: 18 maio 2013.

FRAGA, M.; TOLENTINO, M. A importância do gerenciamento de projetos em pequenas empresas como diferencial competitivo. 2013. Disponível em: <http://www.techoje.com.br/site/techoje/categoria/ detalhe_artigo/673>> Acesso em: 18 maio 2013.

Conex. Ci. e Tecnol. Fortaleza/CE, v. 10, n. 2, p. 61 - 72, jul. 2016
JUNIOR, C.; EVERTON, A. As micro e pequenas empresas no Brasil. Rio de Janeiro: Confederação Nacional do Comércio, 2000. 50 p.

MOREIRA, A.; SILVA, R.; PALMA, M. Análise de gerenciamento de tempo aplicado a um projeto de petróleo. Revista de Gestão e Projetos - GeP, v. 1, n. 2, p. 128 - 146, jul./dez. 2010.

PANIGAS, I. Apostila Gestão do Tempo. Brasília: Instituto de Pós-graduação - IPOG, 2012. 84 p.

PIMENTEL, A. Desvendando o MS Project 2007. São Paulo: Digerati Books, 2008. 112 p.

PINTO, A. Estudo de Benchmarking em

Gerenciamento de Projetos Brasil 2010. 2010.

Disponível em: <http://www.mp.go.gov.br/portalweb/ hp/33/docs/benchmarking_gp_2010_geral.pdf> Acesso em: 25 maio 2013.

PMBOK. A Guide to Project Management Body of Knowledge (PMBOK Guide). 4. ed. [S.1.]: PMI (Project Management Institute), 2008. P. 337. 


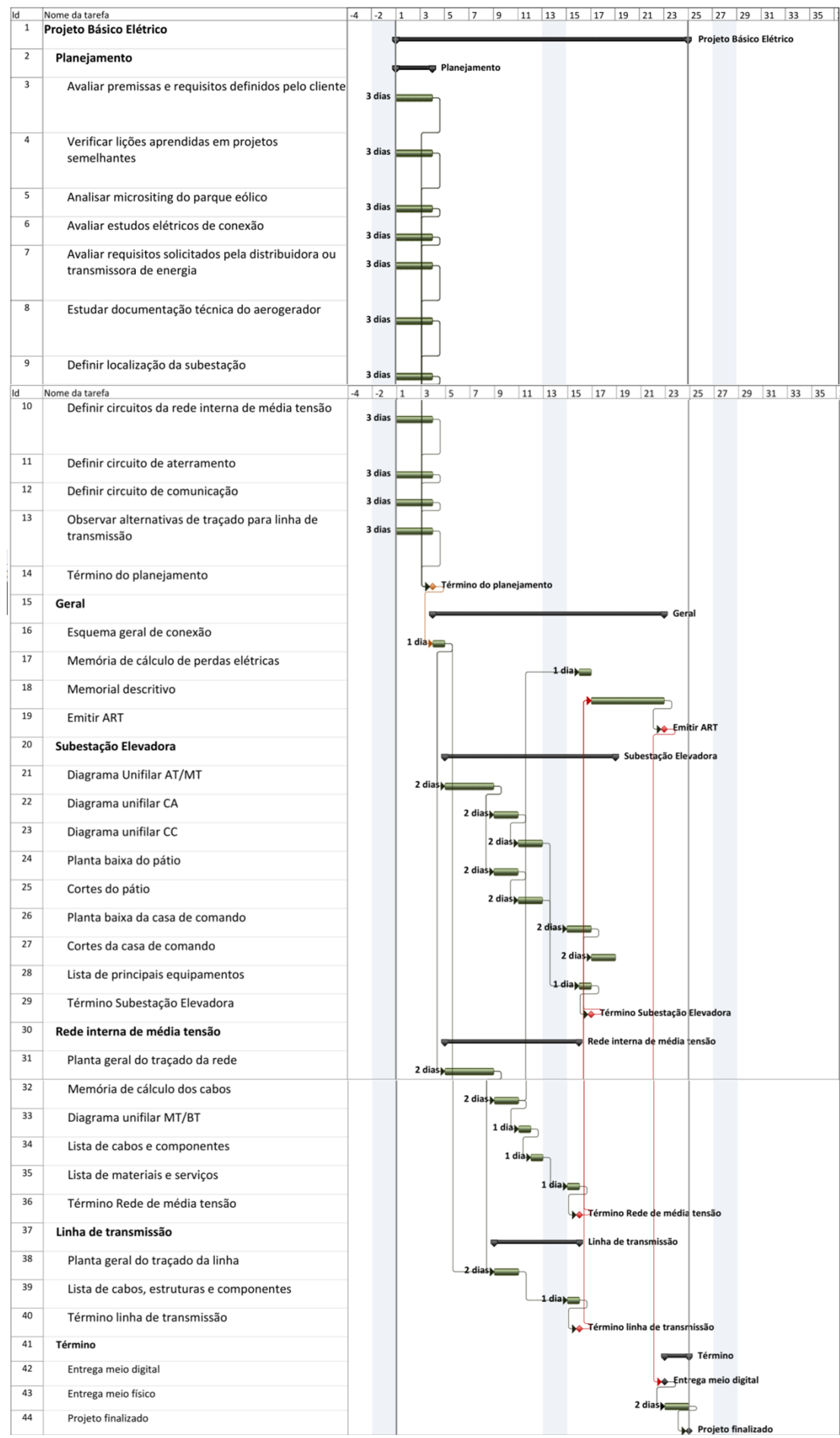

Figura 3: Cronograma do projeto básico. 


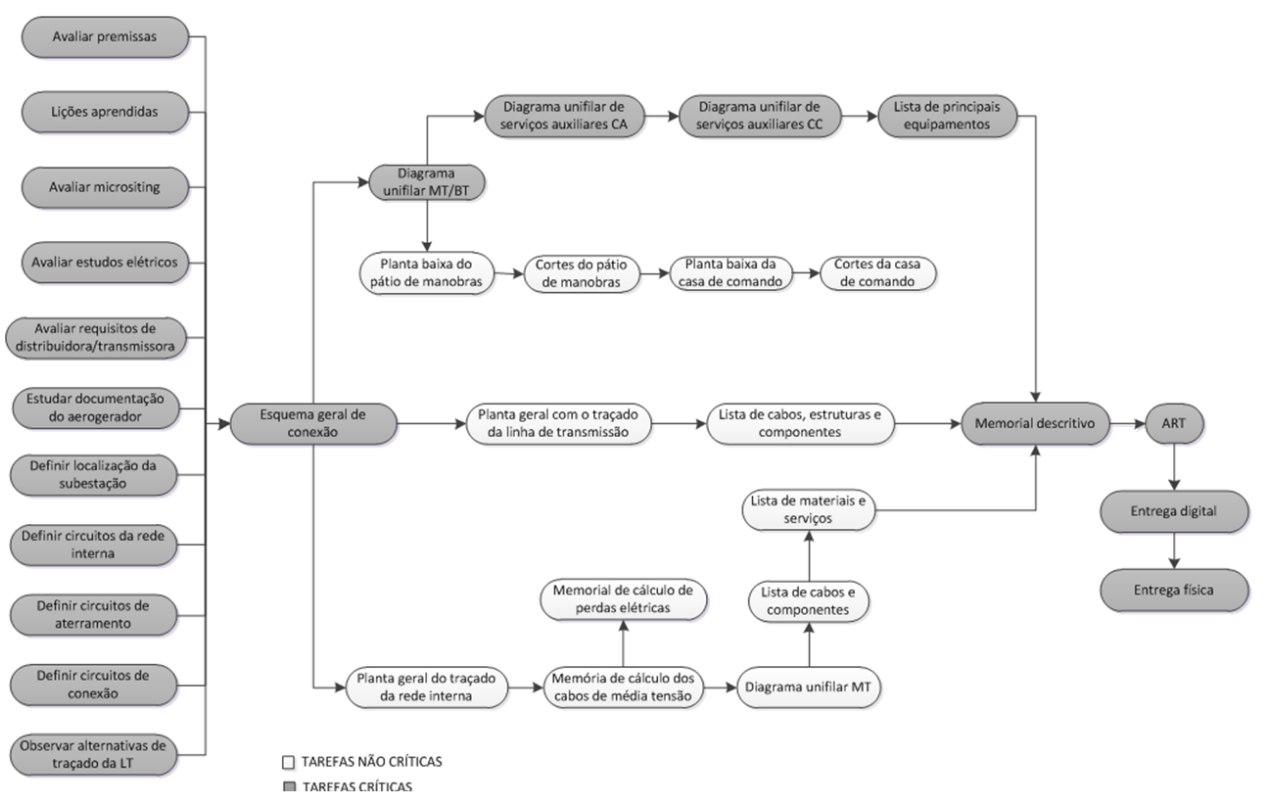

Figura 4: Caminho crítico do projeto básico. 